\title{
Development of $S_{1}$ inbred lines and estimation of inbreeding depression in two maize (Zea mays L.) populations
}

\author{
Zia Ullah ${ }^{1}$, Wasif Ullah Khan ${ }^{2}$, Mukhtar Alam ${ }^{1}$, Hidayat Ullah ${ }^{1 *}$ and Ali \\ Bahadar $^{3}$ \\ 1. Department of Agriculture, The University of Swabi-Khyber Pakhtunkhwa Pakistan \\ 2. Department of Plant Breeding \& Genetics, The University of Agriculture-Peshawar Pakistan \\ 3. Department of Agronomy, Pir Mehar Ali Shah Arid University of Agriculture, Rawalpindi Pakistan \\ *Corresponding author's email: drhidayat@uoswabi.edu.pk
}

Citation

Zia Ullah, Wasif Ullah Khan, Mukhtar Alam, Hidayat Ullah and Ali Bahadar. Development of $\mathrm{S}_{1}$ inbred lines and estimation of inbreeding depression in two maize (Zea mays L.) populations. Pure and Applied Biology. Vol. 4, Issue 4, 2015, pp 575-583. http://dx.doi.org/10.19045/bspab.2015.44017

Received: 10/08/2015 Revised: 04/11/2015

Accepted: $23 / 11 / 2015$

\section{Abstract}

To know the effect of inbreeding depression, this study was conducted in the Agricultural Experimentation Block of the University of Swabi, during the two cropping seasons of 20132014. The $S_{1}$ inbred lines were developed from two of the maize populations viz. popcorn ('PC') and sweet corn ('SC'). Plant height (PH), ear height (EH), ear length (EL), leaf area (LA), number of leaves (NL) and number of tassel branches (TB) were investigated. Highly significant differences $(\mathrm{P} \geq 0.01)$ were observed for $\mathrm{PH}$ and LA in $\mathrm{S}_{1}$ lines however; this effect was nonsignificant within the parental population. While the rest of the traits did not show any significant variation in the first generation of inbreeding $\left(S_{1}\right)$. Of the developed $20 \mathrm{~S}_{1}$ inbred lines, mean data revealed that maximum reduction in $\mathrm{PH}(169.55 \mathrm{~cm})$ was in the set of inbred lines obtained from 'PC' as compared to that of 'SC' $(159.65 \mathrm{~cm})$. Similarly, reduction of 44.92 $\mathrm{cm}^{2}$ was noticed in LA of 'PC-S1-4' as compared to the lines developed from 'SC'. The results indicated that except $\mathrm{PH}$ and LA, other traits like EH, EL, NL and TB are closely linked and hence in first generation of selfing there was not a significant variation in the $S_{1}$ developed from 'PC' and 'SC'. However, the potential inbred lines need to be re-evaluated for diversity, GCA and SCA when homozygosity is complete in later generations.

Key words: Zea mays L.; Inbred line; Popcorn; Sweet corn; Inbreeding depression.

\section{Introduction}

Botanically, cultivated maize is known as (Zea mays L.) and it belongs to the grass family (Poaceae). It is medium to tall annual plant with an extensive fibrous root system [1]. Maize is one of the widely cultivated crops of the world that is being harvested around the globe each month of the year [2]. It is the crop of interest for breeders, consumers and farmers with diverse usage in our daily life [3]. Besides the cultivated maize, different sub-species of maize have also been reported [4]. It is the world's leading cereal crop with global production of 695 million tones and per unit area yield of $4815 \mathrm{~kg} \mathrm{ha}^{-1}$ [5]. In Pakistan during the year 2011-12, maize was planted on 1083 
thousand hectares with total production of 4271 thousand tons, having an average yield of $3893 \mathrm{~kg} \mathrm{ha}^{-1}$ [6]. Inbred lines are the key input required for the development of high quality hybrids. Most of the developed countries are using the three lines technology exploiting male sterility for the development of hybrids. In Pakistan and other developing countries, the inbreds are randomly developed for this purpose. Though the maize can be grown on all types of soils ranging from sandy to clay; however, medium textured soil of $\mathrm{pH} 6.5$ to 7.5 is more suitable for it [7]. Similarly, due to its protandrous nature, pollen shedding normally begins 1-3 days before the silks have emerged in the same plant and usually continues for a period of several days after the silks are ready to be pollinated, thus making it hard for the breeder to develop the inbred lines. An open-pollinated maize variety consists of a range of heterogeneous genotypes from which homozygous and homogeneous (inbred lines) could be developed [8, 9]. The use of single and double crossed hybrids obtained from inbred lines has transformed the corn industry [10]. This study was undertaken to know the effect of inbreeding on the development of $S_{1}$ inbred lines in two of land races or indigenous populations of popcorn and sweet corn on major agronomic and morphophysiological traits.

\section{Materials and Methods}

The experiment was conducted at the Agricultural Experimentation Block of The University of Swabi during the year 20132014. Two of the experimental population i.e. sweet corn (SC) and popcorn (PC) seeds were obtained from the Cereals Crops Research Institute (CCRI) Pirsabak Nowshera. The seeds were sown in twenty rows with plant to plant and row to row distance of 25 and $75 \mathrm{~cm}$ respectively. Two seeds were used per hill at one-inch depth in soil followed by recommended agronomic practices. Table 1 shows the list of $S_{1}$ inbred lines that were developed from ' $\mathrm{PC}$ ' and 'SC' population respectively as per the procedure previously reported [11].

\section{Data Recording}

Data were recorded on the following agronomic and yield parameters by randomly selecting five plants per line.

\section{Plant height (PH) cm}

Data on plant height was recorded for five randomly selected plants using measuring scale rod. The height was measured from soil level to the upper most node in centimeter (cm).

\section{Ear height (EH) cm}

Data on ear height was recorded for five randomly selected plants using measuring rod. The ear height was considered from ground level to the node bearing the cob/ear and recorded in $\mathrm{cm}$.

\section{Ear length (EL) cm}

Ear length was recorded using a scale meter from the tip to the lowermost grain/base.

\section{Leaf area (LA) $\mathbf{c m}^{2}$}

It was recorded on randomly selected five plants through a scale meter. Measurement was taken on tip, middle, base of leaf no. 4 and 5. The mean of recorded values was then used for calculating the leaf area.

\section{Number of leaves (NL)}

Total number of photo-synthetically active leaves was counted and data recorded on five randomly selected plants.

\section{Number of tassel branches (TB)}

Number of tassel branches was counted on five randomly selected plants for calculating the mean. 
Table 1. Base populations (' $\mathrm{PC}$ ' and ' $\mathrm{SC}$ ') used for the development of $\mathrm{S}_{\mathbf{1}}$ inbred lines during the year 2013-14.

\begin{tabular}{|l|l|}
\hline 'PC' & 'SC' \\
\hline 'PC-S1-1' & 'SC-S1-1' \\
\hline 'PC-S1-2' & 'SC-S1-2' \\
\hline 'PC-S1-3' & 'SC-S1-3' \\
\hline 'PC-S1-4' & 'SC-S1-4' \\
\hline 'PC-S1-5' & 'SC-S1-5' \\
\hline 'PC-S1-6' & 'SC-S1-6' \\
\hline 'PC-S1-7' & 'SC-S1-7' \\
\hline 'PC-S1-8' & 'SC-S1-8' \\
\hline 'PC-S1-9' & 'SC-S1-9' \\
\hline 'PC-S1-10' & 'SC-S1-10' \\
\hline
\end{tabular}

'PC': Popcorn; 'SC': Sweet corn

\section{Procedure for Inbred Lines Development}

The female part (ear/cob) was covered using silk bag prior to silk emergence. Care was taken to avoid any cross-pollination or contamination of pollen during pollination. The tassel was covered in morning and evening. Pollination was started at 11:00 am and continued till 12:30 pm. The silk bag was replaced with tassel bag containing pollen in a way that no foreign pollens could enter the shoot bag or touch the silk of the cob.

Statistical Analysis
Obtained data were subjected to statistical analysis (ANOVA) in RCBD. Statistix ${ }^{\mathrm{TM}}$ (version 8.1) statistical software was used for analysis at the appropriate level of significance.

\section{Results and discussion}

Analysis of variance of the investigated traits of the parental populations

Data recorded for different parameters on the parental populations were statistically analyzed and have been presented in Table 2. It can be seen in Table 2 that all of the morphological traits of the selected parental populations were non-significant $(\mathrm{P} \geq 0.01)$.

Table 2. Variance analysis results of the populations (' $\mathrm{PC}$ ' and ' $\mathrm{SC}$ ') in terms of investigated traits in the year 2012-13

\begin{tabular}{|l|c|c|c|c|c|c|c|}
\hline Sov & Df & PH & CH & NL & CL & TB & LA \\
\hline Rep. & 1 & 34.96 & 3.78 & 3.72 & 0.12 & 3.03 & 1132.10 \\
\hline Populations & 1 & $203.4^{\mathrm{NS}}$ & $6.97^{\mathrm{NS}}$ & $0.03^{\mathrm{NS}}$ & $0.12^{\mathrm{NS}}$ & $1.77^{\mathrm{NS}}$ & $257.05^{\mathrm{NS}}$ \\
\hline Error & 37 & 24.4 & 7.77 & 0.49 & 1.05 & 3.31 & 738.74 \\
\hline Total & 39 & - & - & - & - & - & - \\
\hline CV & - & 3.03 & 4.92 & 5.84 & 6.22 & 6.81 & 9.25 \\
\hline
\end{tabular}

Df: Degree of freedom, PH: Plant Height, CH: Cob Height, NL: Number of leaves, CL: Cob length, TB: Number of tassel Branches, LA: Leaf area 
Mean values for morpho-physiological traits within the parental populations Means of some of the morpho-physiological traits within the two-parental populations have been given in Table 3. Maximum height of $165.14 \mathrm{~cm}$ was attained by the parental population ' $\mathrm{PC}$ ' as compared to $(160.63 \mathrm{~cm})$ of 'SC'. Maximum value for cob height $(57.09 \mathrm{~cm})$, cob length $(16.60$ $\mathrm{cm})$ and leaf area $\left(296.35 \mathrm{~cm}^{3}\right)$ was recorded for the parental population ' $\mathrm{SC}$ '. Variation had been previously observed in traits such as plant height, cob height, leaves and leaf areas in a study conducted on twenty different inbred lines [12]. The parents or base populations selected here had narrow range of variation which was non-significant and hence confirms the findings of other researchers [13].

Table 3. Mean values for PH, CH, NL, CL, TB and LA of the two populations ('PC' and 'SC')

\begin{tabular}{|l|l|l|}
\hline \multirow{2}{*}{ Morpho-physiological Traits } & Mean values & \\
\cline { 2 - 3 } & 'PC' & 'SC' \\
\hline PH & 165.14 & 160.63 \\
\hline CH & 56.255 & 57.090 \\
\hline NL & 12.100 & 12.040 \\
\hline CL & 16.490 & 16.600 \\
\hline TB & 26.725 & 26.725 \\
\hline LA & 291.28 & 296.35 \\
\hline
\end{tabular}

PC: Pop corn,SC: Sweet corn, PH: Plant Height, CH: Cob Height, NL: Number of leaves, CL: Cob length, TB: Number of tassel Branches, LA: Leaf area

ANOVA results, mean squares for morpho-physiological traits within the $S_{1}$ inbred lines derived from the parental populations ('PC' and 'SC')

ANOVA results of the $\mathrm{S}_{1}$ inbred lines derived from ' $\mathrm{PC}$ ' and ' $\mathrm{SC}$ ' have been presented in Table 4 for most of the important traits. Since, these inbred lines were derived from the parental populations with narrow genetic base, therefore, most of traits were found to be non-significant except $\mathrm{PH}$ and LA which were highly significant.

Table 4. Analysis of variance results of the $S_{1}$ inbred lines in-terms of investigated traits in the year 2013-14

\begin{tabular}{|l|c|c|c|c|c|c|c|}
\hline Source of variation & Df & PH & CH & NL & CL & TB & LA \\
\hline Rep. & 1 & 1.26 & 0.009 & 0.009 & 7.02 & 7.22 & 105.95 \\
\hline S $_{\mathbf{1}}$ lines & 19 & $100.4^{* *}$ & $3.69^{\mathrm{NS}}$ & $0.61^{\mathrm{NS}}$ & $3.50^{\mathrm{NS}}$ & $2.65^{\mathrm{NS}}$ & $573.4^{* *}$ \\
\hline Error & 19 & 2.04 & 1.39 & 0.39 & 3.96 & 1.70 & 4.01 \\
\hline Total & 39 & - & - & - & - & - & - \\
\hline CV & - & 0.01 & 2.10 & 5.41 & 12.57 & 9.19 & 0.69 \\
\hline
\end{tabular}

NS: Non-significant, Df: Degree of freedom, PH: Plant Height, CH: Cob Height, 
NL: No. of Leaves, CL: Cob Length, TB: Tassel Branches, LA: Leaf Area

Means and deviation from mean values of parents for the $\mathrm{PH}, \mathrm{CH}$ and $\mathrm{NL}$ of $\mathrm{S1}$ inbred lines.

\section{Plant Height (PH-cm)}

Mean data for $\mathrm{PH}$ and the deviation from parents have been given in Table 5 . Maximum $\mathrm{PH}$ among the $\mathrm{S}_{1}$ lines derived from popcorn was recorded for 'PC-S1-1' $(169.55 \mathrm{~cm})$ while the minimum $\mathrm{PH}$ was recorded for 'PC-S1-4' (150.15 cm). Among the $\mathrm{S}_{1}$ lines derived from ' $\mathrm{SC}$ ', the highest value for $\mathrm{PH}$ was acquired by 'SC-S1-10' $(159.65) \mathrm{cm}$ while the least $\mathrm{PH}$ was recorded for 'SC-S1-2' (144.85) cm. The inbreeding depression or reduction in $\mathrm{PH}$ was also studied. Table 3.4 shows, that the maximum reduction in $\mathrm{PH}$ among the inbred lines derived from 'PC' was recorded for 'PC-S14' $(+14.99) \mathrm{cm}$ while the least difference was observed for 'PC-S1-1' (-4.41).
Similarly, among the inbred lines derived from 'SC', the highest reduction was recorded for 'SC-S1-2' $(15.78 \mathrm{~cm}) \mathrm{cm}$ while the least height difference of $0.98 \mathrm{~cm}$ was noticed for 'SC-S1-10'. It is clear from the means data table that all of the $S_{1}$ inbred lines derived from ' $\mathrm{SC}$ ' have shown certain degree of reduction in their $\mathrm{PH}$ as compared to the parental populations. In case of $\mathrm{S}_{1}$ inbred lines derived from 'PC', there was increase in $\mathrm{PH}$ in one of the line as compared to the parental $\mathrm{PH}$ values. A range of plant height of $110-160 \mathrm{~cm}$ for the inbred lines' has been reported [14]. It has been shown that inbred lines developing least depression contribute positively towards the development of hybrids [15]. Average values of inbreeding depression for plant height were recorded as $21.50 \mathrm{~cm}[\mathbf{1 4}, \mathbf{1 6}]$.

Table 5. Mean values and deviation of $\mathrm{S}_{1}$ inbred lines ('PC' and 'SC') for the PH, CH and NL.

\begin{tabular}{|c|c|c|c|c|c|c|}
\hline \multirow{2}{*}{$\mathbf{S}_{\mathbf{1}}$ lines ['PC'] } & \multicolumn{2}{|c|}{ PH } & \multicolumn{2}{|c|}{ CH } & \multicolumn{2}{c|}{ NL } \\
\cline { 2 - 7 } & $\mathbf{M e a n s}$ & Deviation & Means & Deviation & Means & Deviation \\
\hline 'PC-S1-1' & $\underline{\mathbf{1 6 9 . 5 5}}$ & -4.41 & 56.8 & -0.55 & 12.3 & -0.2 \\
\hline 'PC-S1-2' & 161.55 & 3.59 & 56.8 & -0.55 & 10.8 & 1.3 \\
\hline 'PC-S1-3' & 163.7 & 1.44 & 54.7 & 1.55 & 11.1 & 1 \\
\hline 'PC-S1-4' & 150.15 & $\underline{\mathbf{1 4 . 9 9}}$ & 56.7 & -0.45 & 11.5 & 0.6 \\
\hline 'PC-S1-5' & 157.6 & 7.54 & 55 & 1.25 & 11 & 1.1 \\
\hline 'PC-S1-6' & 162.25 & 2.89 & 56.2 & 0.05 & 12.1 & 0 \\
\hline 'PC-S1-7' & 154.35 & 10.79 & 56.1 & 0.15 & $\mathbf{1 2 . 6}$ & -0.5 \\
\hline 'PC-S1-8' & 159.9 & 5.24 & 54.2 & 2.05 & 11.7 & 0.4 \\
\hline 'PC-S1-9' & 153.1 & 12.04 & $\mathbf{5 8}$ & -1.75 & 11.8 & 0.3 \\
\hline 'PC-S1-10' & 160.5 & 4.64 & 57 & -0.75 & 11.9 & 0.2 \\
\hline \multirow{2}{*}{$\mathbf{S}_{\mathbf{1}}$ lines ['SC'] } & & $\mathbf{P H}$ & & $\mathbf{C H}$ & & $\mathbf{N L}$ \\
\hline & $\mathbf{M e a n s}$ & $\mathbf{D e v i a t i o n}$ & $\mathbf{M e a n s}$ & $\mathbf{M e a n s}$ & $\mathbf{D e v i a t i o n}$ & Means \\
\hline 'SC-S1-1' & 150.75 & 9.88 & $\underline{\mathbf{5 8 . 7}}$ & -1.61 & 12.1 & -0.06 \\
\hline 'SC-S1-2' & 144.85 & $\underline{\mathbf{1 5 . 7 8}}$ & $\mathbf{5 7 . 3}$ & -0.21 & $\underline{\mathbf{1 2 . 6}}$ & -0.56 \\
\hline 'SC-S1-3' & 145.65 & 14.98 & 54 & 3.09 & 11.7 & 0.34 \\
\hline 'SC-S1-4' & 155.4 & 5.23 & 56.5 & 0.59 & 11.8 & 0.24 \\
\hline 'SC-S1-5' & 147.95 & 12.68 & 55.5 & 1.59 & 11.9 & 0.14 \\
\hline 'SC-S1-6' & 159.4 & 1.23 & 55 & 2.09 & 12 & 0.04 \\
\hline 'SC-S1-7' & 157.2 & 3.43 & 54.6 & 2.49 & 10.8 & 1.24 \\
\hline 'SC-S1-8' & 148.6 & 12.03 & 54.9 & 2.19 & 11.1 & 0.94 \\
\hline 'SC-S1-9' & 152.05 & 8.58 & 58.2 & -1.11 & 11.5 & 0.54 \\
\hline 'SC-S1-10' & $\underline{\mathbf{1 5 9 . 6 5}}$ & 0.98 & 56.5 & 0.59 & 11 & 1.04 \\
\hline
\end{tabular}




\section{Cob Height $(\mathbf{C H}) \mathbf{c m}$}

Mean data for $\mathrm{CH}$ and the deviation from the parental lines ('PC' and 'SC') have been given in Table 5. Maximum and minimum values for $\mathrm{CH}$ among the $\mathrm{S}_{1}$ lines derived from 'PC' were recorded for 'PC-S1-9' (58 $\mathrm{cm})$ and 'PC-S1-4' (54.2 cm). Similarly, the maximum and minimum cob height of 58.7 and $54 \mathrm{~cm}$ were recorded respectively for $\mathrm{S}_{1}$ lines 'SC-S1-1' and 'SC-S1-3' derived from ' $\mathrm{SC}$ '. Maximum and minimum reduction in $\mathrm{CH}$ among the inbred lines derived from $\mathrm{PC}$ were recorded for 'PC-S1-8' $(+2.05 \mathrm{~cm})$ and 'PC-S1-4' (-0.45 cm). Similarly, among the inbred lines derived from ' $\mathrm{SC}$ ', the highest and least reduction was recorded for ' $\mathrm{SC}$ S1-3' $(+3.09 \mathrm{~cm})$ and $(-1.11 \mathrm{~cm})$ was noted for 'SC-S1-9'. The effect of inbreeding depression was slightly higher in ' $\mathrm{SC}$ ' rather than ' $\mathrm{PC}$ '. Heterosis effects in maize $\mathrm{F}_{1}$ hybrids for days to maturity, plant height, ear height, kernels ear-1 ${ }^{-1}$ 1000-grain weight and grain yield $\mathrm{kg} \mathrm{ha}^{-1}$ were found to be depressed severely during inbred lines development process. However, theses parameters boosted effectively in recombination process [17]. Average values of inbreeding depression for plant height and ear-height were recorded as $21.50 \mathrm{~cm}$ and $4.87 \mathrm{~cm}$, respectively [16].

\section{Number of leaves (NL)}

Leaves are the industry of photosynthetic activities. Both in 'PC' and ' $\mathrm{SC}$ ' derived $\mathrm{S}_{1}$ lines; the maximum NL (12.6) was recorded for 'PC-S1-7' and 'SC-S1-2'. Similarly, the minimum NL (10.8) was recorded for 'PCS1-3' and 'SC-S1-7' (Table 5). Maximum and minimum reduction in NL within the inbred lines derived from ' $\mathrm{PC}$ ' was recorded for 'PC-S1-2' (+1.3) and 'PC-S1-1' (-0.2) respectively. Similarly, among the inbred lines derived ' $\mathrm{SC}$ ' the highest and lowest reduction was recorded for ' $\mathrm{SC}-\mathrm{S} 1-7$ ' $(+1.24)$ and for 'SC-S1-1' (-0.06). Again like other traits, the effect of inbreeding depression was high in ' $\mathrm{SC}$ ' population.
Inbred line with maximum NL would be of benefit for the best combination in hybrid development [18]. Loss of 20-30\% has been reported for NL in local and exotic maize inbred lines developed and characterized in Peshawar valley [11].

Cob length $(\mathrm{CL}) \mathrm{cm}$

Mean data for CL and deviation from the parents are presented in Table 3.5. Upper $(16.65 \mathrm{~cm})$ and lower $(12.9 \mathrm{~cm})$ limit of CL was observed respectively in inbred lines 'PC-S1-6' and 'PC-S1-4' both developed from 'PC'. Similarly in $S_{1}$ inbred lines obtained from SC, the highest and lowest $\mathrm{CL}$ was recorded for 'SC-S1-3' (16.65 cm) and 'SC-S1-9' (12.9 cm). Regarding inbreeding depression the maximum loss was recorded for 'PC-S1-4' $(+3.59 \mathrm{~cm})$ and the minimum for 'PC-S1-2 $(-0.01 \mathrm{~cm})$ '. For the 'SC', highest reduction was recorded for 'SC-S1-9' (3.7 cm) while the least CL difference of $-0.05 \mathrm{~cm}$ was obtained for SCS1-3. As stated above this trait was also highly influenced by the inbreeding. Previously, positive correlation with the cycle of generation of inbreeding; and, decrease to $12 \mathrm{~cm}$ in CL has been reported in maize $[19,20]$.

\section{Tassel branches (TB) No.}

Maximum TB, as is evident from Table 6, were observed among $S_{1}$ inbred line obtained from 'PC' which was 15.3 for 'PCS1-5', while fewer tassel branches (12.2) were recorded for 'PC-S1-8'. Among the ' $\mathrm{SC}$ ' maximum number of $\mathrm{TB}$ were counted for 'SC-S1-8'(15.8) and the fewest number of TB were recorded for 'SC-S1-1'as 12.6. Surprisingly the reduction or depression was high in 'PC' than that of 'SC' for this important trait. The environment also played an important role in the expression of traits like tassel branches [13]. Loss of vigour in inbred line development has been found to is associated with the pedigree of the plants [21]. 
Leaf area (LA) $\mathbf{c m}^{2}$

'PC-S1-4' $\left(336.2 \mathrm{~cm}^{2}\right)$ and 'PC-S1-7' (264.1 $\mathrm{cm}^{2}$ ) had the widest and narrowest LA respectively (Table 6). Maximum reduction in LA among the inbred lines derived from 'PC' was recorded for 'PC-S1-7' (+27.18) $\mathrm{cm}^{2}$ while the least differentiation was observed for 'PC-S1-2' (-1.92) $\mathrm{cm}^{2}$. Similarly, among the inbred lines derived from ' $\mathrm{SC}$ ' the highest and least reduction was recorded for 'SC-S1-2' $(+17.05) \mathrm{cm}^{2}$ and 'SC-S1-5' $\left(-0.75 \mathrm{~cm}^{2}\right)$. This trait was also affected more than that of ' $\mathrm{SC}$ ' for the depression. Inbred lines developed through conventional means in CCRI, Pir-Sabaq showed severe reduction in leaf area however, the good results in terms of midparent heterosis for traits like leaf area was also observed [22].

Table 6. Mean values and deviation of S1 inbred line (PC and SC) for CL, TB and LA.

\begin{tabular}{|c|c|c|c|c|c|c|}
\hline \multirow{2}{*}{$\begin{array}{c}\text { S1 lines } \\
\text { ['PC'] }\end{array}$} & \multicolumn{2}{|c|}{ CL } & \multicolumn{2}{c|}{ TB } & \multicolumn{2}{c|}{ LA } \\
\cline { 2 - 7 } & Means & Deviation & Means & Deviation & Means & Deviation \\
\hline 'PC-S1-1' & 16.9 & -0.41 & 13.3 & 13.42 & 271.6 & 19.68 \\
\hline 'PC-S1-2' & 16.5 & -0.01 & 14.5 & 12.22 & 293.2 & -1.92 \\
\hline 'PC-S1-3' & 16.7 & -0.21 & 14.8 & 11.92 & 288.05 & 3.23 \\
\hline 'PC-S1-4' & 12.9 & 3.59 & 14.4 & 12.32 & 336.2 & -44.92 \\
\hline 'PC-S1-5' & 14 & 2.49 & 15.3 & 11.42 & 313.05 & -21.77 \\
\hline 'PC-S1-6' & 16.65 & -0.16 & 12.6 & 14.12 & 283.15 & 8.13 \\
\hline 'PC-S1-7' & 15.3 & 1.19 & 16 & 10.72 & 264.1 & 27.18 \\
\hline 'PC-S1-8' & 16.65 & -0.16 & 12.2 & 14.52 & 274.7 & 16.58 \\
\hline 'PC-S1-9' & 16.3 & 0.19 & 14.4 & 12.32 & 312.55 & -21.27 \\
\hline 'PC-S1-10' & 16.55 & -0.06 & 12.8 & 13.92 & 300.35 & -9.07 \\
\hline S1 lines & \multicolumn{2}{|c|}{ CL } & & TB & & LA \\
\cline { 2 - 7 } ['SC'] & Means & Deviation & Means & Deviation & Means & Deviation \\
\hline 'SC-S1-1' & 16.65 & -0.05 & 12.6 & 14.12 & 302.15 & -5.8 \\
\hline 'SC-S1-2' & 15.3 & 1.3 & 14 & 12.72 & 279.3 & 17.05 \\
\hline 'SC-S1-3' & 16.65 & -0.05 & 14.8 & 11.92 & 288.05 & 8.3 \\
\hline 'SC-S1-4' & 16.3 & 0.3 & 13.9 & 12.82 & 275.85 & 20.5 \\
\hline 'SC-S1-5' & 16.55 & 0.05 & 14.6 & 12.12 & 297.1 & -0.75 \\
\hline 'SC-S1-6' & 16.9 & -0.3 & 14.1 & 12.62 & 291.9 & 4.45 \\
\hline 'SC-S1-7' & 16.5 & 0.1 & 16.3 & 10.42 & 275.25 & 21.1 \\
\hline 'SC-S1-8' & 16.7 & -0.1 & 15.8 & 10.92 & 299.75 & -3.4 \\
\hline 'SC-S1-9' & 12.9 & 3.7 & 13.5 & 13.22 & 298 & -1.65 \\
\hline 'SC-S1-10' & 14 & 2.6 & 14.7 & 12.02 & 297.15 & -0.8 \\
\hline
\end{tabular}




\section{Conclusion and Recommendations}

$\mathrm{S}_{1}$ inbred lines developed from ' $\mathrm{SC}$ ' population showed deviation from the parental line. Maximum reduction was noted for traits such as $\mathrm{PH}, \mathrm{CL}$ and $\mathrm{CH}$ as compared to that of the inbred lines developed from 'PC', which showed minimum reduction for above-mentioned parameters and maximum reduction for $\mathrm{NL}$, LA and tassel branches as compared to ' $\mathrm{SC}$ '. The response of $S_{1}$ inbred lines developed from ' $\mathrm{PC}$ ' and ' $\mathrm{SC}$ ' within the same microenvironment suggests that the environment has greater effect on the expression of trait variation as shown by different response of $\mathrm{S}_{1}$ 's of ' $\mathrm{PC}$ ' as compared to $\mathrm{S}_{1}$ 's of 'SC'. Thus it can be concluded that different populations respond differently during the process of inbred line development. It can also be concluded that while investigating under drought conditions the breeders dealing with ' $\mathrm{PC}$ ' and ' $\mathrm{SC}$ ' populations should consider the traits that are expressed fully. Moreover, the characters least responsive to inbreeding should be evaluated in later generations when fixation of genes approximately complete.

\section{Authors' contributions}

Conceived and designed the experiments: $\mathrm{H}$ Ullah. Performed the experiments: Z Ullah \& W Khan. Analyzed the data: A Bahadar. Contributed reagents/materials/analysis tools: W Khan. Wrote the paper: H Ullah \& M Alam.

\section{References}

1. Jan KC (2006). Genome Mapping and Molecular Breeding in Plants. Springer Berlin Heidelberg New York, 1(3): 135135.

2. Mangelsdorf PC \& Reeves RG (1939). The origin of Indian corn and its relatives. Agricultural and Mechanical College of Texas.
3. Troyer F (2001). Cereals. $6^{\text {th }}$ Eds of Springer-Verlag Berlin Heidelberg, 3(1): 49-50.

4. Shah Z, I Munir, S Ali, A Iqbal, S Mumtaz, R Nwaz \& Swati ZA (2009). Genetic diversity of Pakistani maize genotypes using chromosome specific simple sequence repeat (SSR) primer sets. Afr J Biotech 8(3): 375-379.

5. Saeed MT, M Saleem \& Afzal M (2000) Genetic analysis of yield and its components in maize diallel crosses (Zea mays L.). Intl J Agric Bio 2(4): 376-378.

6. Anonymous (2012). Pakistan Bureau of Statistics. Maize: area, production and yield. Agricultural Statistics of Pakistan, 2011-12. Federal Bureau of Statistics, Statistics Division, Islamabad, Pakistan. 1-273.

7. Pohelman MJ (1972). Breeding Asian Field Crops with Special Reference to Crops of India.

8. East EM (1908). Inbreeding in corn. Rep. Conn. Agric. Exp. Stn. 419-428.

9. Shull GH (1908). The composition of a field of maize. Journal of Heredity 1: 296-301.

10. Acquaah G (2007). Principles of Plant Genetics and Breeding in Chapter "Breeding hybrid cultivars". Blackwell Publishing 350 Main Street, Malden, MA 02148-5020, USA. 334-335.

11. Singh P (2007). Essentials of plant breeding. Kalyani publishers, 1-60.

12. Ullah H, IH Khalil, G Hassan \& Ullah I (2006). Performance of local and exotic inbred lines of maize under agroecological conditions of Peshawar. Sarhad J. Agric 22(3): 409-414.

13. Rahman H, SMA Shah, Durrishawar, I Nawaz, I Amin \& Iqbal M (2008). Evaluation of testcrosses of $S_{1}$ lines for morphology and maturity traits in maize. Sarhad J. Agric 24(4): 619-624. 
14. Ahmad N, HU Rahman, F Mahmood, S Ahmad, R Ali \& Khan A (2012). Evaluation of half-sib families derived from maize variety Sarhad white for grain yield and agronomic traits. Middle-East J. Medicinal Plants Res 1(4): 80-85.

15. Ali F, SI Ahmed, HU Rahman, M Noor, MK Yasir, I Ullah \& Yan J (2012). Heterosis for yield and agronomic attributes in diverse maize germplasm. Aus J Crop Sci 6(3): 455-462.

16. Ahmad M, SKhan, F Ahmad, NH Shah \& Akhtar N (2010). Evaluation of $99 \mathrm{~S}_{1}$ lines of maize for inbreeding depression. Pak J Agri Sci 47(3): 209213.

17. Amanullah SJ, M Mansoor \& Khan MA (2011). Heterosis studies in diallel crosses of maize. Sarhad J Agric 27(2): 207-211.

18. Rahman H, N Islam, IH Khalil, Durrishawar \& Rafi A (2007). Multiple traits selection in a maize population derived from maize variety Dehqan. Sarhad J Agric 23(3): 637-640.
19. Stevanovic M, Snezana, M Drinic, G Stankovic, V Kandic, Z Camdzija, N Grcic \& Crevar M (2012). Analyses of variance and correlation among yield and yield components of maize hybrids and their parental inbred lines. Maize Research Institute, Slobodan a Bajica 1, 11185 ZemunPolje, Serbia.

20. Noor M, H Rahman, Durrishawar, M Iqbal, SMA Shah \& Ullah I (2010). Evaluation of maize half sib families for maturity and grain yield attributes. Sarhad J Agric 26(4): 545.

21. Liu K, M Goodman, S Muse, JS Smith, E Buckler \& Doebley J (2003). Genetic structure and diversity among maize inbred lines as inferred from DNA microsatellites. Genetics 165(4): 21172128.

22. Iqbal M, K Kha, H Rahman, IH Khalil, H Sher \& Bakht J (2010). Heterosis for morphological traits in subtropical maize (Zea mays L). Maydica 55(1): 41-48. 